\title{
Perfil epidemiológico das doenças causadas pelo Aedes aegypti nos Distritos Sanitários de São Luís - MA
}

\author{
Epidemiological profile of diseases caused by Aedes aegypti in the Sanitary Districts of \\ São Luís - MA
}
Perfil epidemiológico de las enfermedades causadas por Aedes aegypti en los Distritos Sanitarios de São Luís - MA

Eliane Coelho Rodrigues dos Santos ${ }^{1 *}$ Simone Cynamon Cohen ${ }^{1}$, Renato da Gama-Rosa Costa ${ }^{1}$.

\section{RESUMO}

Objetivo: Descrever as características epidemiológicas dos Distritos Sanitários de São Luís - Maranhão, com enfoque nas três doenças transmitidas pelo Aedes aegypti: dengue, zika e chikungunya. Métodos: Estudo, de caráter observacional, descritivo, retrospectivo, seccional, se baseia na observação dos dados registrados pelo Sistema de Informações de Agravos e Notificação (SINAN), fornecidos pela Secretária Municipal de Saúde de São Luis (SEMUS). Resultados: No ano de 2011, houve uma maior notificação da dengue, sendo 5.378 casos. O gênero feminino predominou e a faixa etária com o maior número de notificações foi 20 a 39 anos. As notificações do zika vírus e chikungunya se iniciaram em 2015 com pico epidêmico em 2016. O Distrito Sanitário Bequimão o segundo mais populoso, notificou maior número de casos. Conclusão: A prevalência das doenças causadas pelo Aedes aegypti apresenta nas três arboviroses, variação endêmica relacionada ao adensamento populacional e às condições sanitárias locais, que, neste artigo, privilegiará o estudo da capital maranhense, em que se registra carência de infraestrutura sanitária e de abastecimento de água, merecendo a atenção das autoridades sanitárias e atuação permanente da população.

Palavras-chave: Saúde pública, Saneamento, Aedes aegypti, Distrito sanitário.

\begin{abstract}
Objective: To describe the epidemiological characteristics of the San Luis Health Districts - Maranhão, focusing on the three diseases transmitted by Aedes aegypti: dengue, zika and chikungunya. Methods: An observational, descriptive, retrospective, sectional study based on the observation of data recorded by the Diseases Information and Notification System (SINAN), provided by the Municipal Health Secretary of São Luis (SEMUS). Results: In 2011, there was a greater notification of dengue, with 5,378 cases. The female gender predominated and the age group with the highest number of notifications was 20 to 39 years. Notifications of zika virus and chikungunya started in 2015 with an epidemic peak in 2016. Bequimão Health District, the second most populous, reported the highest number of cases. Conclusion: The prevalence of diseases caused by Aedes aegypti presents in the three arboviruses, endemic variation related to population density and local health conditions, which, in this article, will privilege the study of the capital of Maranhão, where there is a lack of sanitary infrastructure and supply of water, deserving the attention of the health authorities and permanent action of the population.
\end{abstract}

Keywords: Public health, Sanitation, Aedes aegypti, Sanitary district.

\section{RESUMEN}

Objetivo: Describir las características epidemiológicas de los Distritos de Salud de San Luis - Maranhão, centrándose en las tres enfermedades transmitidas por Aedes aegypti: dengue, zika y chikungunya. Métodos: Estudio observacional, descriptivo, retrospectivo, seccional basado en el nota de datos registrados por el Sistema de Información y Notificación de Enfermedades (SINAN), proporcionado por la

1 Escola Nacional de Saúde Pública (ENSP), Rio de Janeiro - RJ.

*E-mail: elianecoelhorodrigues13@gmail.com 
Secretaría Municipal de Salud de São Luis (SEMUS). Resultados: En 2011, hubo una mayor notificación de dengue, con 5.378 casos. Predominó el sexo femenino y el grupo de edad con mayor número de notificaciones fue de 20 a 39 años. Las notificaciones de virus zika y chikungunya comenzaron en 2015 con un pico epidémico en 2016. El Distrito de Salud de Bequimão, el segundo más poblado, reportó el mayor número de casos. Conclusión: La prevalencia de enfermedades causadas por Aedes aegypti presenta en los tres arbovirus, variación endémica relacionada con la densidad de población y las condiciones de salud locales, lo que, en este artículo, privilegiará el estudio de la capital de Maranhão, donde existe una falta de infraestructura y suministro sanitarios de agua, mereciendo la atención de las autoridades sanitarias y la acción permanente de la población.

Palabras claves: Salud pública, Saneamiento, Aedes aegypti, Distrito sanitario.

\section{INTRODUÇÃO}

O Aedes aegypti originário do Egito, na Africa, é um mosquito urbano, transmissor da dengue, chikungunya, zika e da febre amarela urbana, tendo uma relação estreita com o homem, se prolifera em áreas de maior densidade populacional, principalmente em regiões metropolitanas. Por ser próprio das regiões tropical e subtropical. Corroborando Mendonça FA, et al., 2009, atribui vários fatores para a recorrência de epidemias de dengue nos países tropicais e subtropicais destacando-se a proliferação do mosquito Aedes aegypti, o rápido crescimento demográfico associado a intensa e desordenada urbanização.

O ciclo de vida compreende o ovo e quatro estágios larvais, a duração depende da temperatura, disponibilidade de alimento entre outras condições, podendo em condições ótimas esse período não exceder cinco dias (BRASIL, 2001). Além de um estágio de pupa e a fase adulta, o acasalamento, sendo que as fêmeas fazem o repasto sanguíneo na maioria dos vertebrados com preferência pelo sangue humano.

Segundo Chiaravalloti Neto F, et al. (2007), dengue é um subproduto da urbanização desordenada que se verifica em países de economia emergente. Apresenta grande adaptação à vida urbana e sua propagação é privilegiada devido aos hábitos consumistas modernos advindos principalmente do processo de urbanização acelerada

O Aedes aegypti disseminou o vírus da dengue em todo o Brasil, o que levou à ocorrência de várias epidemias em todas as suas regiões, incluindo as mais urbanizadas e consequentemente mais populosas. Segundo Brasil (2015), o crescimento significativo ocorreu na década de 1990, atingiu um nível mais elevado em 1998, quando foram oficialmente registrados cerca de 530 mil casos.

Houve uma redução acentuada em 1999, no entanto, no início do século em 2002 foi registrado um aumento na incidência do dengue, alcançando 794.219 casos notificados. Brasil (2015), notificou que no Brasil, em 2008, a incidência da doença alcançou aproximadamente 800 casos por 100 mil habitantes.

Segundo a Organização Mundial de Saúde (OMS), estima-se que entre cinquenta a cem milhões de pessoas se infectem com a dengue anualmente em mais de cem países, Por ano, cerca de 550 mil doentes carecem de internação e 20 mil morrem em consequência da doença. Calcula-se que $42 \%$ da população mundial vivam em áreas onde o vírus da dengue pode ser transmitido (WHO, 2012). Hoje mais de $80 \%$ da população mundial corre risco de contrair doenças transmitidas por mosquitos, tais como dengue, zika, chikungunya e malária (OMS, 2017).

A capacidade de transmissão de diversas doenças pelo Aedes Aegypti e sua adaptação para reprodução em coleções de água são características que devem ser priorizadas nas medidas de prevenção, não somente da infecção pelo vírus zika, mas também das demais arboviroses que ele transmite (HENRIQUES CMP, et al., 2016). Portanto, eliminar criadouros do mosquito nas cidades brasileiras, especialmente em locais onde há condições precárias nas habitações e em seu entorno é uma tarefa complexa e que depende da atuação consciente e permanente das populações assim como integração das ações de controle das doenças causadas pelo mosquito. 
A Organização das Nações Unidas (2015), alerta que atualmente cerca de $25 \%$ da população mundial que mora em cidades, vivendo em absoluta pobreza, o que possibilita que sejam verdadeiras portas de infecção.

Com a globalização a população das cidades intensificou processo de mobilização, que permitiu a dispersão de vetores e consequentemente das doenças por eles transmitidas, temos como exemplo a dengue e a introdução de duas novas arboviroses: zika e chikungnya, que assim como a dengue, são transmitidas pelo Aedes aegypti. Acredita-se que esses vírus foram introduzidos no Brasil no período da Copa do Mundo de 2014 (VASCONCELOS PFC, 2015),

Segundo Schuler-Faccini L, et al. (2016), a população brasileira no começo de 2015 avançando para 2016, sofreu um surto do vírus zika - um flavivírus transmitido pelo mosquito Aedes - identificado no nordeste do Brasil.

Das regiões brasileiras, a região Nordeste é uma das mais afetadas pelo vírus da dengue, a população de todos os seus nove estados apresenta um risco muito elevado de infecção, e dos estados que a compõe, o Maranhão é um dos que têm apresentado maior número de casos de dengue. (BRASIL, 2016a; INSTITUTO TRATA BRASIL, 2018).

A cidade de São Luís possui características propicias para ser zona endêmica das doenças causadas pelo Aedes aegypti, entre elas os fatores climáticos compatíveis contribuindo para a proliferação do mosquito. Conforme Fernandes DR, et al. (2013), as graves deficiências em saneamento e o déficit no fornecimento de água geram grandes armazenamentos de água em locais inadequados contribuindo para a reprodução do mosquito.

O mosquito Aedes aegypti foi introduzido em 1969, em São Luís, somente em 1995 os órgãos de saúde detectaram os primeiros casos de Dengue clássica no bairro da Cohab-Anil (GONÇALVES NETO VS e REBÊLO JMM, 2004). Foram implementadas atividades direcionadas ao combate do vetor sem resultados satisfatórios. Segundo os dados da Secretária Municipal de Saúde de São Luís, a primeira epidemia de dengue aconteceu em 1996 com 4.641 casos notificados.

O Brasil, no final de 2014, começa uma nova fase das doenças causadas pelo Aedes aegypti, caracterizada pela expansão crescente da ocorrência dos quatro sorotipos do vírus da Dengue e duas novas infecções o Zika vírus e o vírus Chikungunya (BRASIL,2016). É notória a necessidade de estabelecer uma estratégia de controle para minimizar os impactos causados pelas epidemias.

Existe associação do zika vírus com a microcefalia uma malformação de origem neurológica na qual a circunferência do crânio do bebê não se desenvolve de forma adequada e, consequentemente influencia no desenvolvimento mental da criança provocando alguns déficits cognitivos. Além disso, a doença está associada à Síndrome de Guillain-Barré doença neurológica, autoimune que provoca fraqueza muscular generalizada, que em casos mais graves provoca paralisia da musculatura respiratória. Durante as epidemias, diversas formas de acometimento do sistema nervoso central (SNC) associada à infecção pelo ZIK V foram relatadas, como meningoencefalite e encefalomielite disseminada aguda (BRASIL, 2016).

A chikungunya já foi identificada em mais de 60 países na Ásia, África, Europa e nas Américas. Os mosquitos vetores da chikungunya se espalharam pela Europa e Américas nas últimas décadas. $\mathrm{Na}$ infecção pelo vírus chikungunya, o aspecto mais relevante é o acometimento das articulações com evolução para quadros de artrites crônicas incapacitantes. A febre chikugunya é uma doença causada pelo vírus chikungunya, do gênero Alphavirus, e tem como vetor o mosquito Aedes aegypti (HORCADA ML, et al., 2015).

No Brasil a partir de 2015, com o reconhecimento da circulação autóctone do vírus Zika, o país passou a contar com a possibilidade da ocorrência de surtos e epidemias simultâneas pelos três vírus (BRASIL, 2016). No município de São Luís do Maranhão, a situação da Dengue não é diferente do contexto nacional. 
Na última década o número de casos cresceu, sendo que São Luís, está entre as 16 capitais do Brasil que estão em estado de alerta para um surto das três doenças transmitidas pelo mosquito Aedes aegypti, como mostra o Boletim da SE no 45. (BRASIL, 2015).

É necessário estudar a dinâmica das doenças causadas pelo Aedes aegypti na cidade de São Luís-Ma com vistas a contribuir para o planejamento e as pesquisas do controle do vetor, possibilitando reduzir a magnitude das epidemias e principalmente, os óbitos por esses agravos. Este trabalho objetivou observar a distribuição das doenças causadas pelo Aedes aegypti nos distritos sanitários relacionando as características dos bairros com maior notificação no período estudado e como as características sanitárias e de urbanização, podem contribuir para o favorecimento da proliferação do mosquito vetor, e consequentemente das doenças por ele transmitidas.

\section{MÉTODOS}

Estudo ecológico observacional descritivo, retrospectivo, seccional, tendo como objeto de estudo as doenças causadas pelo mosquito Aedes aegypti dengue, zika vírus e chikungunya nos sete Distritos Sanitários de São Luís, Estado do Maranhão.

Foi utilizado dados secundários registrados nos bancos de dados do Sistema de Informação de Agravos de Notificação (SINAN) a principal fonte de informações relacionadas a doenças no país e a Coordenação do Programa Nacional de Controle do Dengue do Ministério da Saúde, relativos aos aspectos epidemiológicos e da ocorrência e distribuição dos casos das três arboviroses, no período de 2007 a 2017 para dengue e 2015 a 2017 para Zika e Chikungunya.

Os dados sócios demográficos (população do distrito, índice de pobreza, abastecimento de água, rede de esgoto e coleta de lixo do distrito) foram obtidos de base de dados secundários do (IBGE, 2010).

As informações coletadas mediante $o$ instrumento utilizado foram analisadas e agrupadas separadamente em categorias por meio do software Microsoft Excel versão 2010, sendo que a análise e apresentação dos dados ocorreram pela estatística descritiva.

\section{RESULTADOS E DISCUSSÃO}

No período de 2007 a 2017, foram notificados no município de São Luís-MA, 25.124 casos de dengue, sendo que o ano de 2011 notificou 5.378 casos contribuindo com cerca de (53\%) de casos do estado do Maranhão, provavelmente pela presença de novos sorotipos circulantes, com 14 óbitos, destacando-se em relação aos demais anos. Em 2016 houve um novo pico epidêmico, com quase cinco mil casos, conforme ilustra a Figura 1.

Os anos de 2007, 2011 e 2016 registraram os mais elevados índices de notificação do período estudado, com 3.524; 5.368 e 4.804, conforme dados secundários registrados nos bancos de dados do Sistema de Informação de Agravos de Notificação (SINAN) em São Luís-MA. Esses resultados coincidem com os resultados encontrados por outros autores no mesmo período (PINHO ACC, et al., 2016).

Em 2007, houve aumento de casos de Febre hemorrágica da dengue (FHD) possivelmente pela circulação dos três sorotipos - DENV-1, DENV-2 e DENV-3, evidenciando uma epidemia com 118 casos de FHD e 24 óbitos no município de São Luís-MA. A partir de maio de 2010, a incidência da dengue aumentou em $709 \%$ em São Luís, em comparação com o mesmo período do ano anterior. O sistema de vigilância epidemiológica da dengue, no ano de 2011, observou um pico epidêmico com a introdução do DEN-4 e a circulação de 3 sorotipos.

No período de 2009, se observou uma diminuição nas taxas de incidência de dengue, possivelmente por falhas no sistema de notificação, além da possibilidade da banalização da doença pela população que já estaria ciente do tratamento da Dengue não procurando atendimento nas unidades de saúde. Corroborando com esse dado, Vlana DV e Ignotti E, (2013), mostra que a incidência de casos de dengue flutua de acordo com as condições climáticas e está associada a fatores como aumento da temperatura, pluviosidade e umidade relativa do ar. 
Figura 1 - Série histórica do número de casos de dengue notificados em São Luís, MA no período de 2007 a 2017.

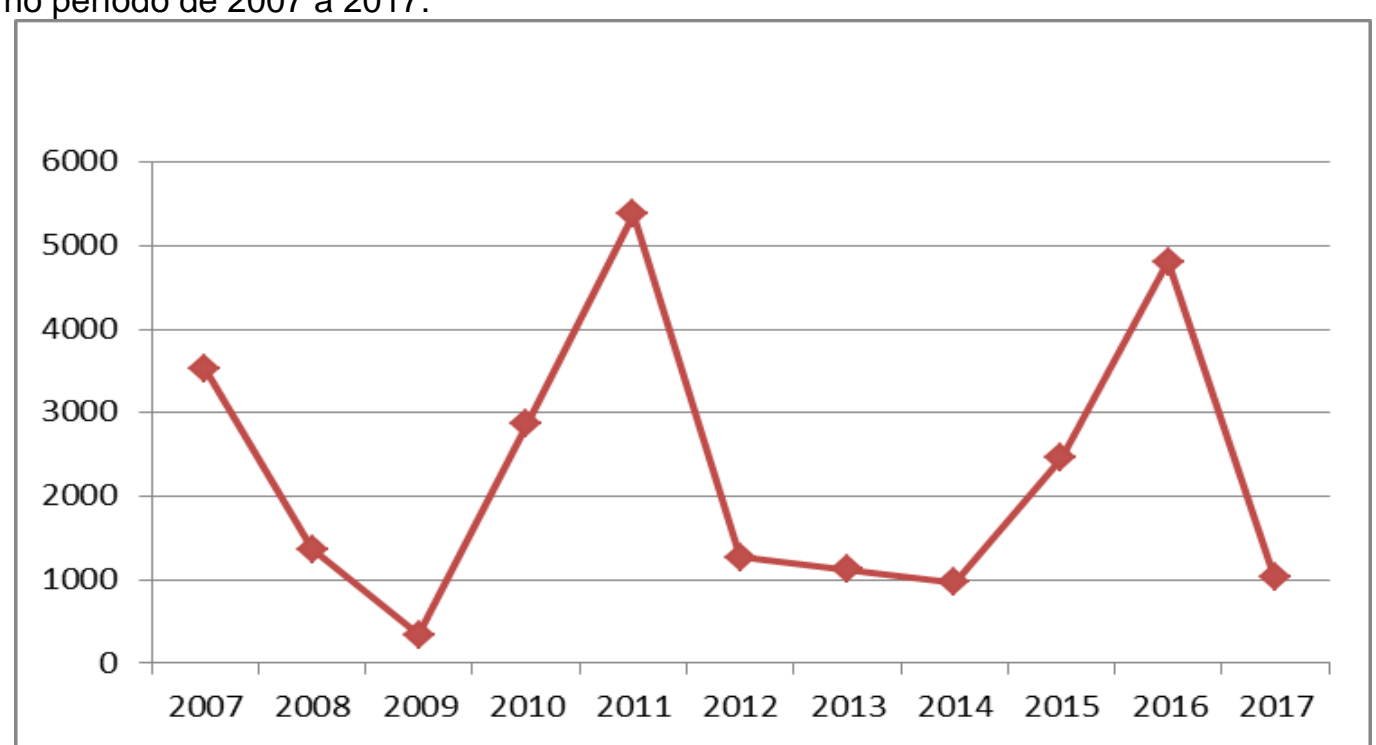

Fonte: Santos ECR, et al., 2020. Dados extraídos do Sistema de Informação de Agravos de Notificação (SINAN).

As notificações por faixa etária ressaltaram maior incidência na faixa de 20 a 29 anos com 5149 casos cerca de $(21 \%)$ população atingida, observa-se que esses dados, basicamente se mantem corroborando com outros autores (GONÇALVES NETO VS e REBELO JMM, 2004; PINHO ACC, et al.,2016) observando que essa faixa etária é representada pela população economicamente ativa, sendo o público mais circulante demonstrado na Figura 2.

A faixa etária de 5 a 9 anos, foi a segunda que mais notificou com 3.858 casos, o maior número de casos nessa faixa etária ocorreu em 2007,2010, 2011 e 2013, provavelmente pela presença de três sorotipos e o aparecimento de um novo sorotipo o DENV 4 em 2011, o aumento da incidência em crianças corrobora com os autores Branco MRFC et al., (2014) que destaca a gravidade e letalidade em menores de 15 anos. A faixa de 39 a 59 notificou 3351 casos sendo a terceira, a incidência diminui bastante a partir da faixa dos 60 anos, embora seja a faixa etária onde o risco de óbito associado a dengue é maior, principalmente quando apresenta comorbidades, que tende ao agravamento do quadro clinico.

Figura 2 - Distribuição da Dengue por faixa etária no período 2007 - 2017.

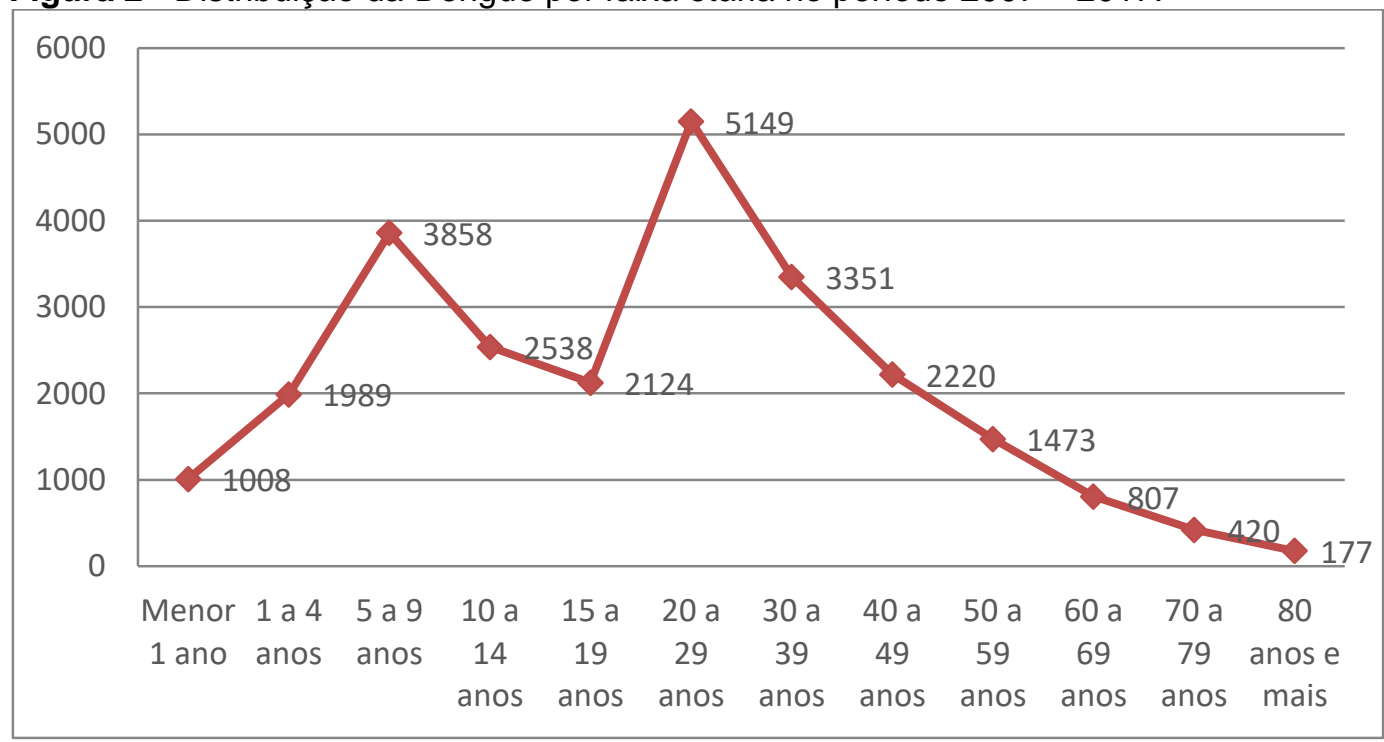

Fonte: Santos ECR, et al., 2020. Dados extraídos do Sistema de Informação de Agravos de Notificação (SINAN). 
A estruturação dos DS surge com a municipalização, funcionando como uma unidade operacional básica do Sistema nacional de saúde, é uma estratégia apoiada pela Organização Mundial de Saúde (OMS), para a melhoria das condições de saúde das populações dos países em desenvolvimento.

Observa-se que no início do período estudado o maior número de casos ocorreram nos DS do ItaquiBacanga e Coroadinho. O DS Itaqui-Bacanga, possui zona urbana com 17 bairros e área de $36 \mathrm{~km}^{2}$ e zona rural com 44 bairros e área de $93 \mathrm{~km}^{2}$ Total de 123.203 habitantes (IBGE, 2010). DS do Coroadinho é formado por Zona Urbana com uma área de $75 \mathrm{~km}^{2}$ e uma zona rural com área: $36 \mathrm{~km}^{2}$, e total de 45 bairros com 134.736 habitantes, são respectivamente áreas periféricas da cidade com a população de baixa renda, e pouca infraestrutura. Conforme ilustra a Tabela 1.

Após 2009 o DS de Bequimão notificou maior número de casos, distrito composto por 64 bairros, todos localizados na zona urbana de São Luís com aproximadamente 247.474 habitantes e extensão de 135 km², o terceiro distrito mais populoso, com melhor renda per capita, maior número de bairros de classe $\mathrm{A}$ e $\mathrm{B}$, todos com periferias ao redor e sem infraestrutura básica necessária principalmente no que se refere à saúde, com situações divergentes nos setores social, demográfico e sanitário. Esse distrito possui características importantes a serem avaliadas: socialmente a população è bastante heterogênea onde a classe mais carente se aglomera ao redor dos grandes condomínios, distante das unidades de saúde, dificultando 0 acesso da população a esses serviços.

Em 2017, o DS da COHAB notificou 372 casos, localiza-se na porção nordeste do município de São Luís, faz limite com o município de São José de Ribamar, possui 40 bairros localizados apenas na zona urbana de São Luís.

Tabela 1 - Distribuição dos casos da dengue por distrito sanitário.

\begin{tabular}{cccccccccccc}
\hline DISTRITO SANITÁRIO & $\mathbf{2 0 0 7}$ & $\mathbf{2 0 0 8}$ & $\mathbf{2 0 0 9}$ & $\mathbf{2 0 1 0}$ & $\mathbf{2 0 1 1}$ & $\mathbf{2 0 1 2}$ & $\mathbf{2 0 1 3}$ & $\mathbf{2 0 1 4}$ & $\mathbf{2 0 1 5}$ & $\mathbf{2 0 1 6}$ & $\mathbf{2 0 1 7}$ \\
\hline DS Tirirical & 206 & 117 & 69 & 427 & 915 & 190 & 176 & 124 & 420 & 579 & 124 \\
DS Centro & 180 & 243 & 31 & 231 & 513 & 111 & 107 & 86 & 349 & 532 & 89 \\
DS Coroadinho & 223 & 299 & 84 & 469 & 730 & 230 & 148 & 154 & 272 & 503 & 66 \\
DS Vila Esperança & 85 & 66 & 22 & 136 & 199 & 84 & 94 & 61 & 81 & 186 & 22 \\
DS Bequimão & 201 & 169 & 53 & 746 & 1530 & 336 & 372 & 299 & 522 & 1.715 & 296 \\
DS Cohab & 169 & 127 & 43 & 494 & 1011 & 237 & 108 & 124 & 682 & 983 & 372 \\
DS Itaqui-Bacanga & 595 & 215 & 36 & 342 & 432 & 72 & 106 & 97 & 93 & 194 & 44 \\
\hline
\end{tabular}

Fonte: Santos ECR, et al., 2020. Dados extraídos do Sistema de Informação de Agravos de Notificação (SINAN).

Conforme observamos no início das notificações (2015) o DS com maior notificação foi o Coroadinho, com 65 casos, contribuindo com (45\%) dos casos. Em 2016 e 2017, o DS Bequimão teve maior notificação respectivamente média de (28\%) e (43\%) dos casos como mostra a Figura 3.

Observamos características distintas nos dois DS, o primeiro com grande número de localidades rurais, baixa infraestrutura, área periférica da cidade, possibilitando a proliferação de criadouros e consequentemente o início de transmissão de uma nova arbovirose como a chikungunya. Outra questão relevante no DS do Coroadinho é o abastecimento de água que é servido por uma rede de canalização de água que atende em média $(87 \%)$ das unidades domiciliares, o resto da população tem acesso à rede pública de abastecimento além de poços e nascentes, entretanto nos bairros que compõem esse distrito há baixa proporção na regularidade do serviço, como consequência da intermitência no abastecimento, a estocagem de água é um procedimento comum, propiciando criadouros potenciais, aumentando a incidência das doenças causadas pelo Aedes Aegypti.

O ano de 2016 e 2017, o DS que mais notificou foi Bequimão, com maior número de casos no bairro do São Francisco, o mais populoso do DS. O gênero feminino notificou 124 (65\%) em 2015 e o sexo masculino com 66 casos. Em 2016 o sexo feminino notificou 2.481 casos (67\%) e 1.230 do sexo masculino. Em 2017 mesmo com a diminuição das notificações o sexo feminino prevaleceu com 164 casos, cerca de (69\%). 
Figura 3 - Distribuição dos casos de Chikungunya nos Distritos Sanitários período de 2015 a 2017.

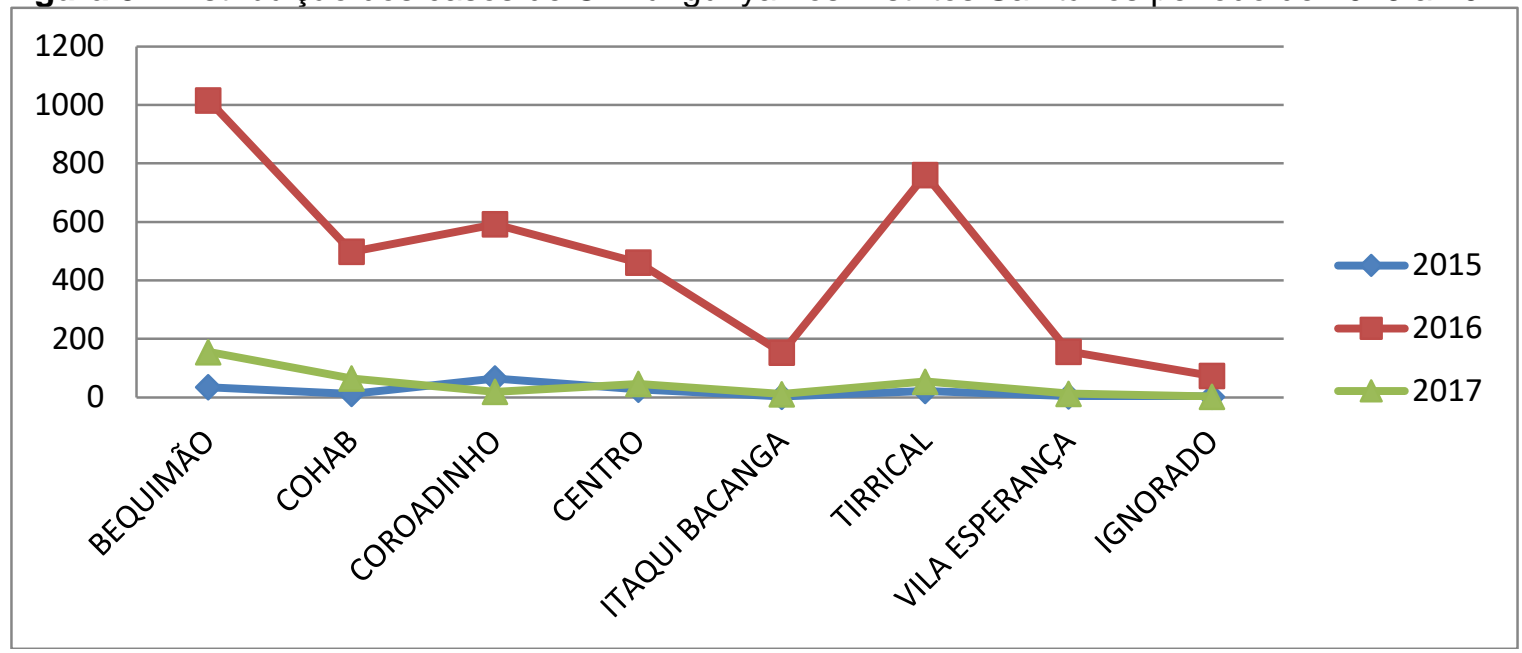

Fonte: Santos ECR, et al., 2020. Dados extraídos do Sistema de Informação de Agravos de Notificação (SINAN).

O vírus zika é pertencente à família Flaviviridae, a mesma dos vírus da dengue, da febre Chikungunya, da flavivírus febre do Nilo Ocidental, da febre amarela, entre outros. Considerado um arbovírus, pois é principalmente transmitido por meio da picada do mosquito Aedes aegypti.

A distribuição anual dos casos do zika vírus em São Luís, conforme mostra a Figura 4, teve sua introdução com 37 casos notificados em 2015, se observa que (43\%) dos casos ocorreram no DS do Bequimão, sendo o bairro do São Francisco, notificou 12 casos (75\%) dos casos. O ano de 2016 foi o período de maior notificação do zika vírus, o DS do Bequimão foi onde ocorreu maior número de casos 771, maior notificação no Bairro do São Francisco 460 (16\%), seguido do DS da Cohab 622 casos. O DS Tirirical apesar de ter a maior população notificou 487 casos. Os DS que registraram menor número de casos foram Vila Esperança com 136 e DS Itaqui Bacanga com 178 casos, são o segundo e o terceiro DS com menor população. O DS Centro, com a menor população notificou 261 casos do zika vírus.

O distrito sanitário do Bequimão apresenta baixa proporção na regularidade do serviço de abastecimento de água $(41,1 \%)$. Como consequência da intermitência no abastecimento, a estocagem de água é um procedimento comum, que possibilita aumento dos criadouros do mosquito.

Figura 4 - Distribuição do zika virus por DS no período de 2015- 2017.

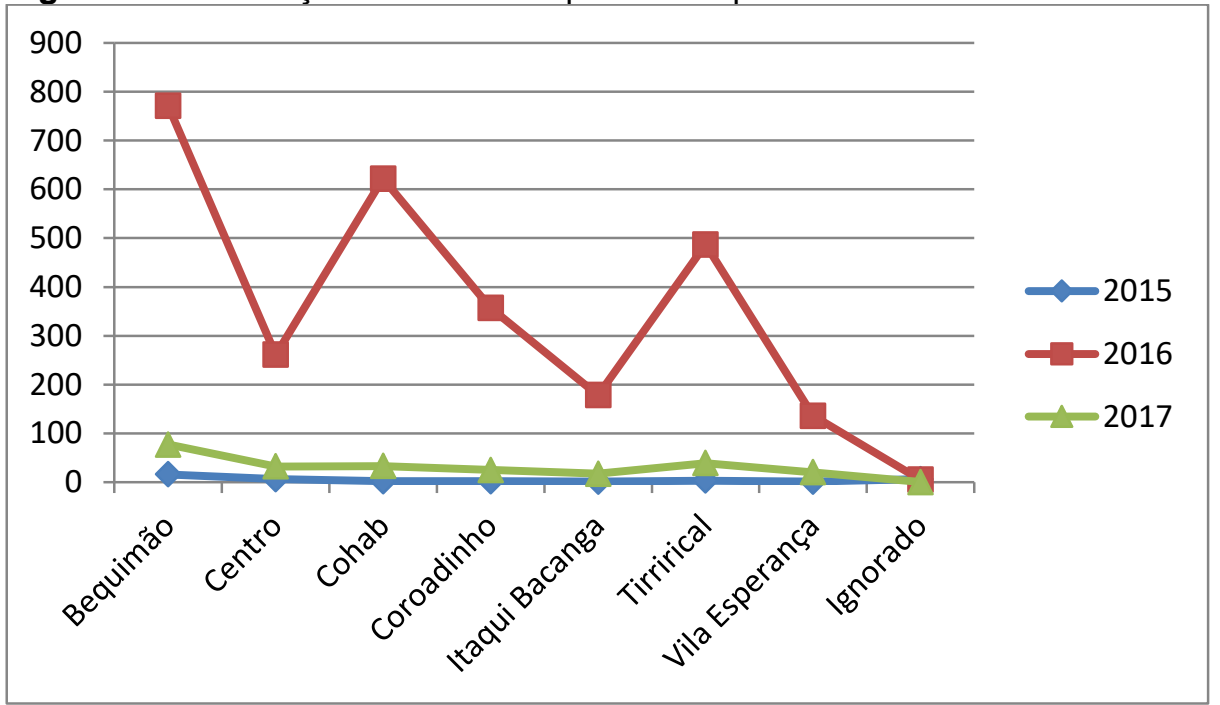

Fonte: Santos ECR, et al., 2020. Dados extraídos do Sistema de Informação de Agravos de Notificação (SINAN). 
A infecção de mulheres grávidas que é um dos principais riscos do zika virus, pela relação com a microcefalia uma malformação que faz com que o cérebro dos bebês não se desenvolva de maneira adequada e outras anomalias neurológicas. No período estudado 584 gestantes contraíram a infecção por ZIK V, sendo 2016, a maior notificação 525 casos. No primeiro trimestre de gravidez (100 casos), período de formação do tubo neural. Cestudo Pregnancy Outcomes after ZIKA Infection in French Territories in the Americas afirma: "um risco indiscutível de anormalidade neurológica quando a mulher desenvolve a infecção durante o primeiro trimestre de gravidez", esse é o período de maior risco, levando em $(3,7 \%)$ dos casos a uma microcefalia grave no bebê. Conforme ilustra a Figura 5.

No segundo trimestre de gravidez foram notificados 283 gestantes e 133 no terceiro trimestre. $O$ ano de 2017, 58 gestantes contraíram infecção por ZIKV, 14 casos no primeiro trimestre e 39 no segundo e 5 no terceiro trimestre. O primeiro ano de notificação somente uma gestante foi infectada no primeiro trimestre de gravidez.

Em 2015, houve um aumento considerável na prevalência da síndrome congênita do zika vírus em São Luís. Observamos que de 2015 a 2017, houve predomínio do zika vírus no sexo feminino, possuindo o agravante que o zika vírus está associado a outras doenças neurológicas principalmente pelo risco da doença para mulheres em idade reprodutiva visto a sua relação com a Microcefalia para o bebê durante a gestação.

Essas evidências corroboram com o reconhecimento da relação entre os casos notificados e o vírus zika. Segundo Cunha V, et al., (2016), esses dados da transmissão vertical do ZIKV estão sobre investigação. O MS tem elaborado orientações específicas para assistência às gestantes e aos recémnascidos com microcefalia, além de ações de vigilância epidemiológicas constantes.

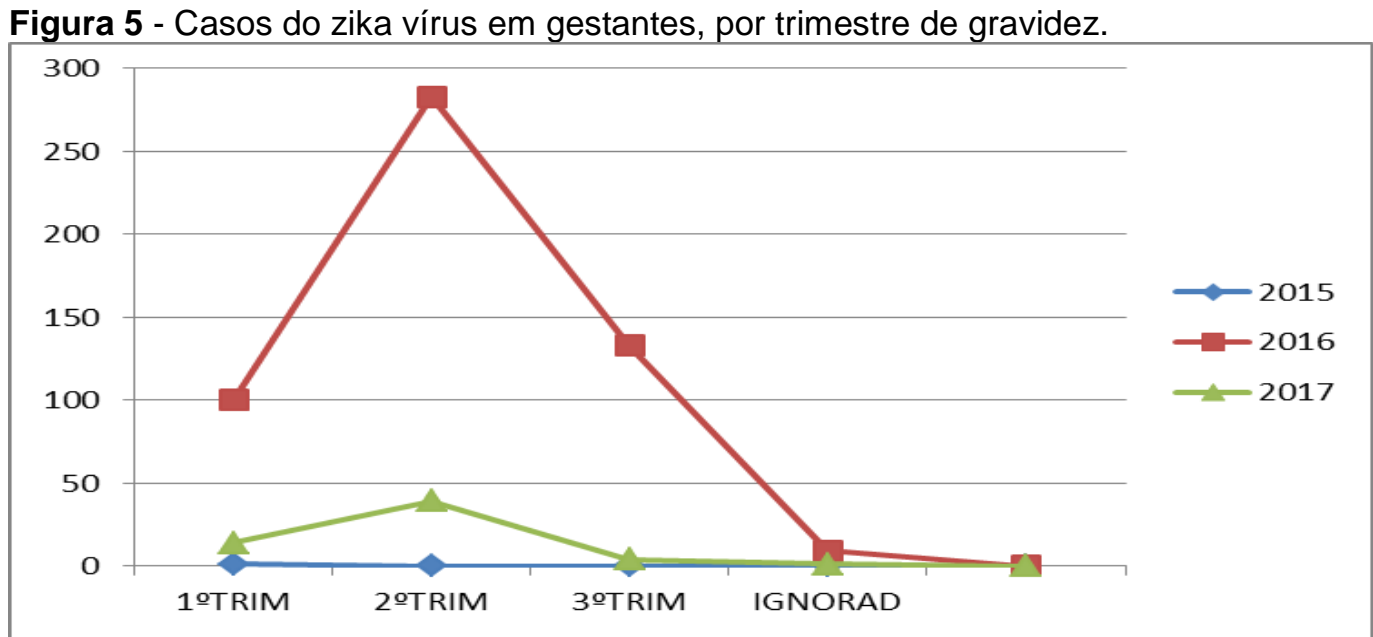

Fonte: Santos ECR, et al., 2020. Dados extraídos do Sistema de Informação de Agravos de Notificação (SINAN).

\section{CONSIDERAÇÕES FINAIS}

O presente estudo revela que São Luís, continua sendo área endêmica das patologias estudadas tendo como principal fator o processo de urbanização com inúmeras deficiências sanitárias, além das influências climáticas favoráveis. Os DS que mais notificaram as doenças causadas pelo Aedes aegypti possuem maior densidade populacional associado a carências sanitárias que possibilitam os focos do mosquito propiciando sua reprodução, temos como exemplo o DS do Bequimão. O estudo propõe a necessidade de subsidiar estratégias de controle das autoridades sanitárias, promovendo a educação para a saúde melhorando as condições de prevenção para a população mais suscetível as doenças causadas pelo Aedes aegypti, possibilitando a continuidade nas ações de combate ao vetor que devem ser realizadas com a atuação consciente da população. 


\section{AGRADECIMENTOS}

Agradecemos a Universidade Estadual do Maranhão pelo apoio financeiro na forma de bolsa para o desenvolvimento do trabalho.

\section{REFERÊNCIAS}

1. BARRETO ML, TEIXEIRA MG. Dengue no Brasil: situação epidemiológica e contribuições para uma agenda de pesquisa. Estudos Avançados, 2008; 22: 53-72.

2. BRANCO MRFC, et al. Risk factors associated with death in Brazilian children with severe dengue: a case-control study. Clinics São Paulo, 2014; 69(1): 55-60.

3. BRASIL. Ministério da Saúde. Fundação Nacional de Saúde. Dengue: instruções para pessoal de combate ao vetor: manual de normas técnicas. - 3. ed. rev. - Brasília, 2001.

4. BRASIL. Ministério da Saúde. Secretária de Vigilância em Saúde. Protocolo de vigilância e resposta à ocorrência de microcefalia relacionada à infecção pelo vírus zika. $2015 . \quad$ Disponível em:<http://portalsaude.saude.gov.br/images/pdf/2015/dezembro/09/Microcefalia---Protocolo-de-vigilancia-e-resposta---vers-0-1----09dez2015-8h.pdf>. Acesso em: 25 jul. 2019.

5. BRASIL. Ministério da Saúde. Secretaria de Vigilância em Saúde. Relatório da Reunião internacional para implementação de alternativas para o controle do Aedes aegypti no Brasil. Boletim Epidemiológico. 2016 a.

6. BRASIL. Ministério da Saúde. Agência Nacional de Vigilância Sanitária. Recomendações técnicas ao Sistema Nacional de Vigilância Sanitária para colaborar no combate ao Aedes aegypti e prevenção e controle da Dengue, Chikungunya e infecção pelo vírus Zika [Internet]. Brasília: Agência Nacional de Vigilância Sanitária; 2016. Disponível em: Disponível em: http://aprav.com.br/wp-content/uploads/2016/04/Cartilha-ANVISA-aedes-1.pdf [ Links ] Acesso em: 15 de maio de 2020.

7. CHIARAVALLOTI NETO F, et al. O programa de controle do dengue em São José do Rio Preto, São Paulo, Brasil: dificuldades para a atuação dos agentes e adesão da população. Cad. Saúde Pública, Rio de Janeiro, 2007; 23(7): 16561664.

8. CUNHA V, et al. ZIKA: abordagem clínica na atenção básica. Brasil: UFMS, 2016.

9. DE OLIVEIRA WK, et al. Zika Virus Infection and Associated Neurologic Disorders in Brazil. N Engl J Med., 2017; 20; 376(16): 1591-1593.

10. DINIZ D. Zika do sertão nordestino á ameaça global- 1.ed. Rio de janeiro; Civilização Brasileira, 2016; 192.

11. FERNANDES DR, et al. Epidemiologia da dengue em São Luís - Maranhão, Brasil, 2000 a 2007. Caderno de Pesquisa, 2013; 20: 2.

12. GATHERER D, KOHL A. Zika Vírus: A previously slow pandemic spreads rapidly. Througen the Americas J Gen Virol. 2016; 97(2): 269-73.

13. GONÇALVES NETO VS, REBÊLO JMM. Aspectos epidemiológicos do dengue no Município de São Luís, Maranhão, Brasil, 1997-2002. Cad. Saúde Pública, Rio de Janeiro, 2004; 20(5): 1424-1431.

14. HENRIQUES CMP, et al. Desafios para o enfrentamento da epidemia de microcefalia. Epidemiol. Serv. Saúde, Brasília, 2016; 25(1): 07-10.

15. HOEN B, et al. Pregnancy outcomes after ZIKV infection in French Territories in the Americas. N Engl. J Med. 2018; 378: 985-994.

16. HORCADA ML, et al. Chikungunya fever. Rheumatic manifestations of an emerging disease in Europe. Reumatol Clin., 2015; 11: 161-164.

17. IBGE. Instituto Brasileiro de Geografia e Estatística. IBGE Censo Demográfico 2010. Disponível em: http://www.cidades.ibge.gov.br/xtras/perfil.php?lang= Acesso em 15/08/2018

18. MENDONCA, FA, et al. Saúde pública, urbanização e dengue no Brasil. Soc. nat. (Online), Uberlândia, 2009; 21(3): 257269.

19. NETO VSG, et al. Conhecimentos e atitudes da população sobre dengue no Município de São Luís, Maranhão, Brasil, 2004. Cad. Saúde Pública, 2006; 22: 2191-2200.

20. OMS. Organização Mundial da Saúde. Doenças transmitidas por insetos matam mais deum milhão por ano. 2016. Disponível em: http://agenciabrasil.ebc.com.br/internacional/noticia/2016-05/doencas-transmitidas-por-insetos-matammaisde-um-milhao-por-ano. Acesso em: 08/11/19.

21. OPAS. Organização do Trabalho da Representação da OPAS/OMS no Brasil 2009-2012./Organização Pan-Americana da Saúde. Brasília, 2009. OPAS/OMS. Zika nas Américas: confira as respostas para as perguntas mais frequentes sobre 0 vírus. Disponívelem<http://www.paho.org/bra/index.php?option=com_content\&view=article\&id=4978:Zika-nas-amacopyricas-confira-as-respostas-para-as-perguntas-mais-frequentes-sobre-o-va-rus\&ltemid=816>. Acesso em 20 jul. 2019.

22. PINHO ACC, et al. Epidemiologia do vírus do dengue em São Luís, maranhão, no período DE 2002 a 2012 . Revista de Patologia Tropical / Journal of Tropical Pathology, 2016; 45(3): 243-255.

23. RIBEIRO AF, et al. Associação entre incidência de dengue e variáveis climáticas. Rev. Saúde Pública, 2006; 4: 671-676.

24. SCHÜLER-FACCINI L, et al. Possible association between Zika vírus-Brazil, 2015. Morbidity and Mortakity Weekly Report., 2016.<Disponível em: http://www.dacex.ct.utfpr.edu.br/11_erislan ribeiro. htm> Acesso em: 12/06/2019.

25. STAGG D, HURST HM. Zika Virus and Pregnancy. Nurs Womens Health, 2016; 20(3): 299-304.

26. TAUIL PL. Condições para a transmissão da febre do vírus chikungunya. Epidemiologia e Serviços de Saúde, $2014 ; 20$ 23(4): 773-774.

27. VASCONCELOS PFC. Doença pelo vírus Zika: um novo problema emergente nas Américas? Revista Pan-Amazônica de Saúde, 2015; 6(2): 9-10.

28. VIANA DV, IGNOTTI E. The ocurrence of dengue and weather changes in Brazil: A systematic review. Rev BRAS Epidemiology, 2013; 16: 240-256.

29. WHO. World Health Organization. Global alert and response: dengue/dengue haemorrhagic fever. 2012. Disponível em <http:/www.who.int/csr/disease/dengue/en/>. Acesso em 15/03/2019. 